\title{
Acrosome reaction: relevance of zona pellucida glycoproteins
}

\author{
Satish K Gupta and Beena Bhandari
}

During mammalian fertilisation, the zona pellucida (ZP) matrix surrounding the oocyte is responsible for the binding of the spermatozoa to the oocyte and induction of the acrosome reaction (AR) in the ZP-bound spermatozoon. The AR is crucial for the penetration of the ZP matrix by spermatozoa. The ZP matrix in mice is composed of three glycoproteins designated ZP1, ZP2 and ZP3, whereas in humans, it is composed of four (ZP1, ZP2, ZP3 and ZP4). ZP3 acts as the putative primary sperm receptor and is responsible for AR induction in mice, whereas in humans (in addition to ZP3), ZP1 and ZP4 also induce the AR. The ability of ZP3 to induce the AR resides in its C-terminal fragment. $\mathbf{O}$-linked glycans are critical for the murine ZP3-mediated AR. However, N-linked glycans of human ZP1, ZP3 and ZP4 have important roles in the induction of the AR. Studies with pharmacological inhibitors showed that the ZP3-induced AR involves the activation of the $\mathrm{G}_{\mathrm{i}}$-coupled receptor pathway, whereas ZP1- and ZP4-mediated ARs are independent of this pathway. The ZP3-induced AR involves the activation of T-type voltage-operated calcium channels (VOCCs), whereas ZP1- and ZP4-induced ARs involve both T- and L-type VOCCs. To conclude, in mice, ZP3 is primarily responsible for the binding of capacitated spermatozoa to the ZP matrix and induction of the AR, whereas in humans (in addition to ZP3), ZP1 and ZP4 also participate in these stages of fertilisation. Asian Journal of Andrology (2011) 13, 97-105; doi:10.1038/aja.2010.72; published online 1 November 2010

Keywords: acrosome reaction; fertilisation; oocyte; signalling pathways; spermatozoa; zona pellucida glycoproteins

\section{INTRODUCTION}

Mammalian fertilisation is a highly synchronized process that involves a complex series of interactions between the spermatozoon and the egg, culminating in their unison. The initial steps in fertilisation involves the binding of the spermatozoon to the zona pellucida (ZP) matrix surrounding the egg, followed by induction of the acrosome reaction (AR) in the zona-bound spermatozoon, a pre-requisite for penetration of the ZP matrix by the spermatozoon. The spermatozoon acrosome is a Golgi-derived organelle that forms a cap over the anterior two-thirds of its nucleus. The AR involves the fusion of the sperm membrane with the outer acrosomal membrane, resulting in release of the acrosomal contents and exposure of the inner acrosomal membrane on the anterior head of the spermatozoon. Various physiological agents, such as progesterone, serum albumin, follicular fluid, hormones (including biogenic amines), hydrolytic enzymes (particularly proteases), hyaluronic acid and ZP glycoproteins, have been implicated in the induction of the AR. ${ }^{1-3}$ In the present paper, we review the role of the $\mathrm{ZP}$ matrix and its constituents in AR induction. Various downstream signalling pathways involved in the ZP glycoprotein-induced AR will also be discussed. On the basis of the current literature and studies from our group, the salient differences in the ZP glycoprotein-mediated induction of the AR in mouse versus human will be highlighted.

\section{INDUCTION OF AR BY THE ZP MATRIX}

Composition of the ZP matrix

The mammalian $\mathrm{ZP}$ is composed of either three or four glycoproteins (Figure 1). The murine ZP matrix is composed of three glycoproteins designated ZP1 (623 amino acids (aa)), ZP2 (713 aa) and ZP3 (424 aa). ${ }^{4}$ Pig, ${ }^{5}$ cow $^{6}$ and $\operatorname{dog}^{7}$ also have three glycoproteins, but instead of $\mathrm{ZP} 1, \mathrm{ZP} 4$ is present (Figure 1). However, the ZP matrices of rats, hamsters, bonnet monkeys and humans are composed of four glycoproteins: ZP1, ZP2, ZP3 and ZP4. ${ }^{8-13}$ In humans, ZP1 has a 638-aa polypeptide backbone; $Z P 2$ has 745 aa; ZP3 has 424 aa and ZP4 has 540 aa. The ZP glycoproteins are heavily glycosylated and have $N$ - as well as $O$-linked glycans, which have crucial roles in the spermatozoon-ZP interaction and AR induction. ${ }^{14,15}$ The orthologue of the human $Z p 4$ gene is present in the mouse genome as a pseudogene and is, therefore, not expressed in the murine $\mathrm{ZP}$ matrix. ${ }^{7}$ In non-mammalian species, more than four ZP genes have been detected; for example, the chicken genome contains six genes $(Z p 1, Z p 2, Z p 3$, $Z p 4, Z p A X$ and $Z p D),{ }^{16}$ and the Xenopus genome contains five genes $(Z p 2, Z p 3, Z p 4, Z p D \text { and } Z p A X)^{7}$

Induction of the AR by the ZP matrix

Pioneering work by Paul Wassarman's group established that the binding of mouse sperm to the egg $\mathrm{ZP}$ is followed by AR induction. ${ }^{17}$ Solubilized ZPs isolated from unfertilized mouse eggs induce the AR, whereas those isolated from embryos fail to do so. ${ }^{17}$ As observed in murine models, incubation of capacitated human sperm with intact zonae or acid-disaggregated zonae also leads to a significant increase in the AR. ${ }^{18,19}$ Progesterone and follicular fluid have priming effects on the $\mathrm{ZP}$-induced $\mathrm{AR} .{ }^{20}$ In contrast to the mouse $\mathrm{ZP}$, the human $\mathrm{ZP}$ of fertilized oocytes retains its ability to bind sperm and also induce the $\mathrm{AR} .{ }^{21}$ However, the rate of penetration of the human ZP matrix by such acrosome-reacted sperm is much lower than that of human sperm that 


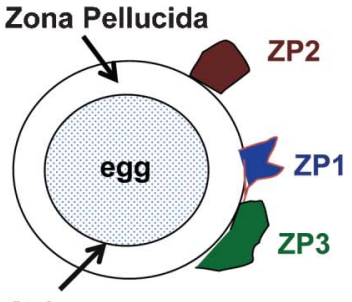

Oolemma

ZP1; ZP2; ZP3

Mouse ZP

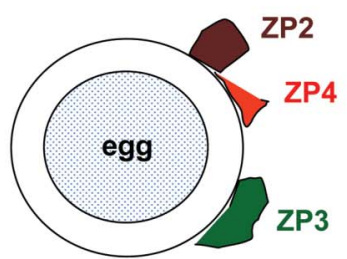

ZP2; ZP3; ZP4

Porcine, bovine and canine ZP

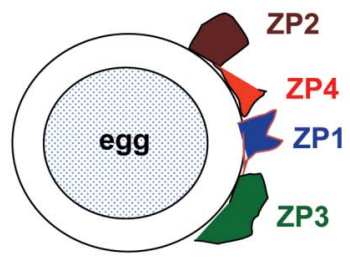

ZP1; ZP2; ZP3; ZP4

Rat, hamster, bonnet

Figure 1 Schematic representation of the composition of the ZP in various mammals: The ZP matrix of the mammalian oocyte is composed of either three or four glycoproteins. The mouse ZP matrix is composed of three glycoproteins, namely, ZP1 (blue), ZP2 (brown) and ZP3 (green). The rat, hamster, bonnet monkey and human ZP matrices are composed of four glycoproteins: ZP1, ZP2, ZP3 and ZP4 (red). The bovine, porcine and canine ZP matrices contain three glycoproteins, with ZP4 replacing ZP1. ZP, zona pellucida.

has reacted with the ZP of unfertilized oocytes. These observations suggest that during fertilisation in humans, the block in polyspermy may also occur at the level of sperm penetration through the ZP matrix. ${ }^{21}$

\section{SIGNALLING EVENTS DURING ZP-MEDIATED ACROSOMAL EXOCYTOSIS}

Binding of a capacitated spermatozoon to the ZP matrix activates transmembrane signals that trigger cellular cascades resulting in the $\mathrm{AR}$ in the zona-bound sperm (Figure 2). At least two different receptor-mediated signalling pathways in the sperm plasma membrane are responsible for $\mathrm{ZP}$-induced acrosomal exocytosis. One is a $\mathrm{G}_{\mathrm{i}}$ proteincoupled receptor that activates the phospholipase $C \beta_{1}\left(P L C \beta_{1}\right)$ mediated signalling pathway, and the other is a tyrosine kinase receptor coupled to PLC $\gamma$ (Figure 2). ${ }^{22}$ Incubation of mouse sperm membrane preparations with heat solubilized ZP prepared from unfertilized mouse eggs leads to a dose-dependent increase in guanosine triphosphate $\gamma$-S binding, as well as GTPase activity, suggesting that the $\mathrm{G}_{\mathrm{i}}$-coupled receptor pathway is involved in the ZP-mediated induction of the AR. ${ }^{23}$ The $\mathrm{ZP}$ may selectively activate $\mathrm{G}_{\mathrm{i} 1}$ and $G_{i 2}$ subtypes of $G_{i}$ in the sperm. ${ }^{24}$ The participation of a second $G$ protein, $\mathrm{G} \alpha_{\mathrm{q} / 11}$, has also been suggested. ${ }^{25}$

$\mathrm{G}_{\mathrm{i}}$ acts as a signal transducing element downstream of the ZP3receptor interactions and couples receptor occupancy to changes in the ionic conductance and/or a variety of intracellular second messenger system cascades whose activation in turn results in the release of acrosomal contents. ${ }^{26}$ One such cascade is likely to be the activation of sodium/proton $\left(\mathrm{Na}^{+} / \mathrm{H}^{+}\right)$exchange pumps, resulting in intracellular alkalinisation. ${ }^{26,27}$ Second messengers include the adenylate cyclasecyclic adenosine monophosphate system, which activates protein kinase A (PKA), leading to the phosphorylation of specific putative proteins involved in acrosomal exocytosis. In addition, the activation of PLC $\beta_{1}$ and/or PLC $\gamma$ leads to an increase in the levels of 1,2-diacylglycerol (DAG) and inositol 1,4,5-triphosphate ( $\left.\mathrm{IP}_{3}\right)$. DAG may stimulate protein phosphorylation through $\mathrm{PKC}$, whereas $\mathrm{IP}_{3}$ may activate intracellular calcium $\left(\left[\mathrm{Ca}^{2+}\right]_{i}\right)$ release through the modulation of $\mathrm{IP}_{3}$-sensitive intracellular calcium stores. ${ }^{25-27}$ Studies with the mouse $\mathrm{ZP}$ solubilized by acid disaggregation have shown that the $\mathrm{ZP}$-induced $\mathrm{AR}$ is a $\mathrm{Ca}^{2+}$-dependent exocytotic event involving an increase in $\left[\mathrm{Ca}^{2+}\right]_{i}$ mediated primarily by $\mathrm{T}$-type voltage-operated calcium channels (VOCCs). ${ }^{28-30}$ A role for L-type VOCCs has also been proposed during induction of the AR. ${ }^{31,32}$ Inhibition of solubi- lized ZP-mediated AR induction by 3-quinuclidinyl benzilate (an antagonist of muscarinic receptors), tyrphostin A-48 (a tyrosine kinase inhibitor) and pertussis toxin (an inhibitor of $G_{i}$ protein signalling) suggests that the binding of the ZP to sperm plasma membrane receptors involves several downstream signalling pathways. ${ }^{28}$

Spermatozoa maintain an inwardly negative membrane potential and conductance through cation channels, producing a depolarizing current. Binding of mouse ZP3 to sperm activates a cation channel (impermeable to anions) that conducts monovalent and divalent cations and leads to sperm membrane depolarisation from about -60 to $-30 \mathrm{mV}$. Depolarisation of the sperm membrane potential opens the T-type VOCCs. However, the voltage-dependent inactivation of $\mathrm{T}$ currents occurs within $50-100 \mathrm{~ms}$ during depolarisation, ${ }^{29,33,34}$ thereby terminating the ZP3-induced calcium influx. The T-type channels may also be modulated by their state of tyrosine phosphorylation during capacitation and ZP3 stimulation. ${ }^{35}$ However, a sustained release of calcium is an absolute requirement for an induction of the AR.

After depletion of calcium from internal stores, store-operated channels, which are voltage-insensitive calcium channels in the plasma membrane, are activated and mediate the second phase of calcium entry, referred to as capacitative calcium entry. ${ }^{36}$ Mammalian transient receptor potential proteins, which are homologues of the Drosophila melanogaster photoreceptor cell transient receptor potential protein, are involved in the ZP3-mediated capacitative calcium entry in mice. ${ }^{36}$ Transient receptor potential homologues have also been located in human sperm. ${ }^{37,38}$ In addition, members of soluble $N$ ethyl maleimide-sensitive factor attachment protein receptor proteins present in the acrosome region of mammalian sperm may also facilitate calcium entry, thereby leading to the AR. ${ }^{39,40}$ The high intracellular free calcium concentration together with DAG leads to membrane fusion and finally acrosomal exocytosis. ${ }^{2,41}$

Induction of the $\mathrm{AR}$ by the solubilized human $\mathrm{ZP}$ depends on extracellular $\mathrm{Ca}^{2+20,42}$ and involves activation of $\mathrm{G}_{\mathrm{i}}$ protein-coupled receptor pathway signalling, ${ }^{20,42-45}$ tyrosine kinases, ${ }^{42} \mathrm{PKA}, \mathrm{PKC}$, phosphoinositide-3 kinase, ${ }^{42,46}$ T-type VOCCs and gamma aminobutyric acid-A receptor-associated chloride channels. ${ }^{42}$

\section{ROLES OF ZP CONSTITUENT GLYCOPROTEINS IN INDUCTION OF THE AR}

It seems that the composition and, consequently, the structure of the mammalian ZP is more complicated than expected because, depend- 


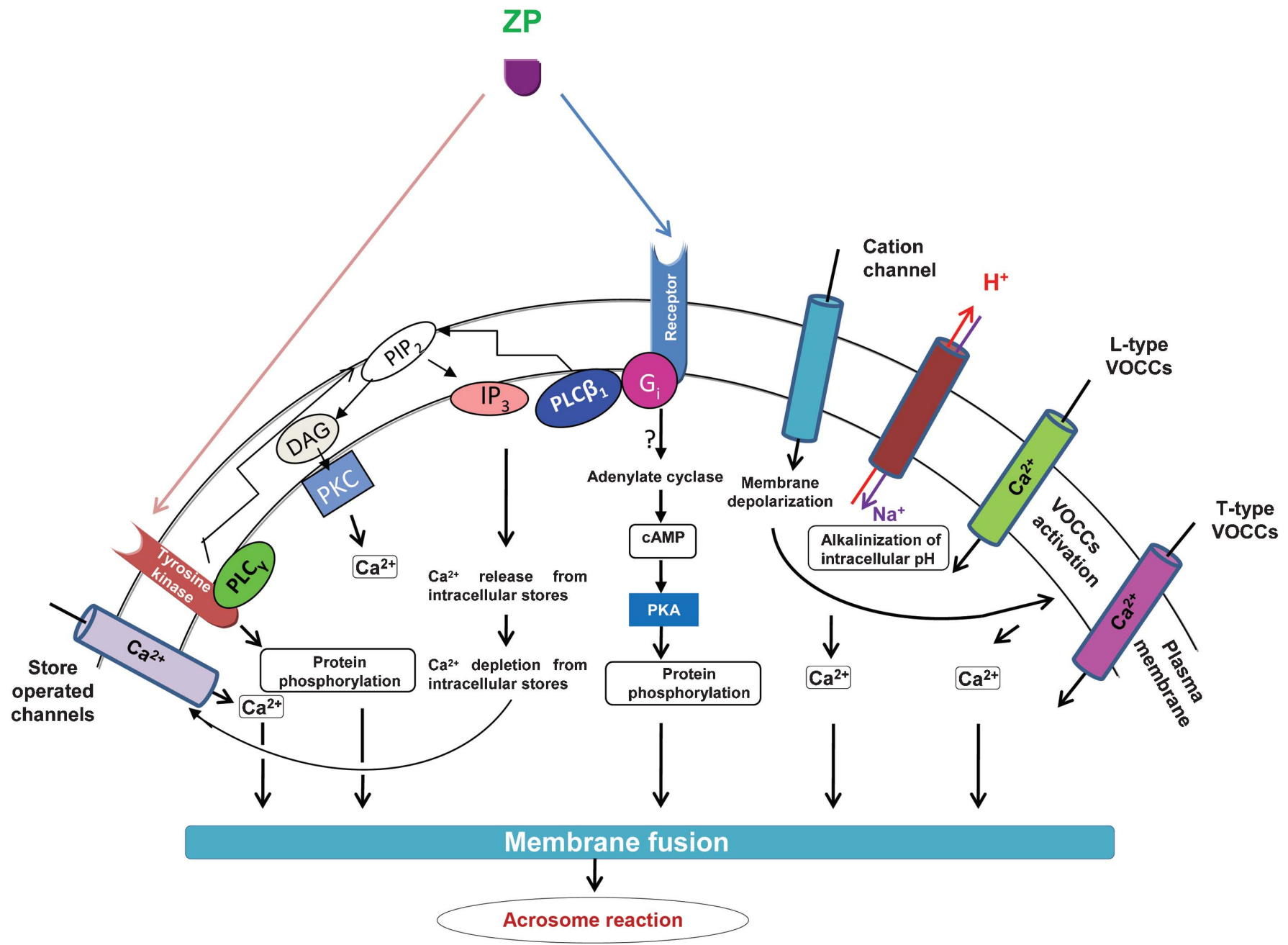

Figure 2 Schematic representation of various signalling pathways involved in ZP-mediated acrosomal exocytosis. Two prominent signalling pathways are known to operate in the sperm membrane upon ZP binding. One is the pertussis toxin sensitive $G_{i}$ protein-coupled receptor linked to PLC $\beta_{1}$. The other is a putative tyrosine kinase receptor coupled to PLC $\gamma$. Receptor activation also induces adenylate cyclase activation, leading to the generation of cAMP and activation of PKA, which phosphorylates and activates downstream effector proteins. Agonist binding also activates cation channels present on the sperm plasma membrane, leading to membrane depolarisation and activation of L- and T-type VOCCs. An increase in intracellular alkalinisation also occurs due to activation of sodium/proton exchange pump that probably increases or amplifies calcium signals. PLC $\beta_{1}$ and PLC $\gamma$ hydrolyse $P I P_{2}$ in the membrane, leading to the generation of IP ${ }_{3}$ and DAG. DAG mediates PKC translocation to the plasma membrane and its activation, whereas $I P_{3}$ mediates calcium entry into the sperm cytosol from intracellular stores. Depletion of calcium from internal stores leads to activation of voltage insensitive SOCs on the sperm cell surface by an undefined mechanism. This mediates another round of calcium entry, which leads to activation of components involved in the fusion of the outer acrosomal membrane with the sperm plasma membrane resulting in the AR. AR, acrosome reaction; cAMP, cyclic adenosine monophosphate; DAG, 1,2-diacylglycerol; PKA, protein kinase A; IP 3 , 1,4,5-inositol triphosphate; PIP ${ }_{2}$, phosphatidylinositol 4,5-bisphosphate; PLC, phospholipase C; SOC, store-operated channel; VOCC, voltage-operated calcium channel; ZP, zona pellucida.

ing on the species: (i) it is formed by three or four ZP glycoproteins (Figure 1); (ii) in the three-glycoprotein model, it can be formed by ZP1, ZP2 and ZP3 or ZP2, ZP3 and ZP4 (Figure 1); and (iii) the protein responsible for sperm binding and $A R$ induction may vary across species. To delineate the roles of individual zona proteins, various groups have either used the purified protein from a native source (which makes it difficult to rule out minor contamination from other egg-associated or zona proteins) or the recombinant protein. Using recombinant protein ensures that it is not contaminated by other zona proteins. However, the recombinant proteins may not have the conformation and glycosylation of its native counterpart. Nonetheless, both approaches have been used to delineate the role of individual zona proteins in binding sperm and inducing the AR.
Table 1 summarizes the role of individual zona proteins in sperm binding and AR induction.

\section{ZP1}

In a murine model, ZP1 purified from ZPs of unfertilized eggs does not interfere significantly with the binding of sperm to eggs in vitro, suggesting that ZP1 does not bind to sperm. ${ }^{47}$ Furthermore, ZP1 purified from mouse eggs has no significant effect on AR compared with the respective control. ${ }^{17}$ However, it has been postulated that cross-linking by ZP1, the filaments formed by ZP2-ZP3 heterodimers, may provide stability and structural integrity to the $\mathrm{ZP}$ matrix. ${ }^{48}$ Studies in quail and chicken have shown that ZP1 (dimeric in chicken) is capable of inducing the AR. ${ }^{49,50}$ Recent studies from our group have 
Table 1 Zona pellucida glycoproteins involved in sperm binding and induction of the acrosome reaction in mice and humans

\begin{tabular}{|c|c|c|c|c|}
\hline \multirow[b]{2}{*}{ Species } & \multirow[b]{2}{*}{ ZP protein } & \multicolumn{2}{|l|}{ Function } & \multirow[b]{2}{*}{ Reference } \\
\hline & & Binding to capacitated spermatozoa & Induction of acrosome reaction & \\
\hline Mice & Native ZP3 & Yes & Yes & 17,47 \\
\hline \multirow[t]{10}{*}{ Humans } & ZP1 & & & \\
\hline & $\begin{array}{l}\text { Baculovirus-expressed recombinant protein } \\
\text { ZP3 }\end{array}$ & Yes & Yes & 31 \\
\hline & Baculovirus-expressed recombinant ZP3 & Yes & Yes & 52,53 \\
\hline & & ND & Yes & 61 \\
\hline & & ND & Yes & 32 \\
\hline & Mammalian-expressed recombinant ZP3 & ND & Yes & 62 \\
\hline & & Yes & Yes & 63 \\
\hline & & ND & Yes & 64 \\
\hline & & ND & Yes & 32 \\
\hline & Native ZP4 & Yes & Yes & 55,60 \\
\hline
\end{tabular}

Abbreviations: ND, not done; ZP, zona pellucida.

shown that both Escherichia coli- and baculovirus-expressed recombinant human ZP1 conjugated to fluorescein isothiocyanate bind to the anterior head of capacitated human spermatozoa (Table 1). ${ }^{31}$ Baculovirus-expressed recombinant $\mathrm{ZP1}$ also generates a dosedependent increase in acrosomal exocytosis, which involves activation of both T- and L-type VOCCs. The failure of E. coli-expressed recombinant human $\mathrm{ZP} 1$ to induce the AR suggests that glycosylation of ZP1 is critical for its ability to induce the AR. Induction of the AR by ZP1 does not depend on activation of the $G_{i}$ protein-coupled receptor pathway, whereas human solubilized ZP- as well as ZP3- (described below) mediated ARs involve activation of the $G_{i}$ protein. Inhibition of PKA and $\mathrm{PKC}$ significantly reduces the $\mathrm{ZP1}$-mediated induction of the $\mathrm{AR}{ }^{31}$

\section{ZP2}

Mouse ZP2 purified from ZPs of unfertilized eggs does not interfere with sperm-egg binding or with induction of the AR. ${ }^{17,51}$ Monoclonal and polyclonal antibodies against mouse ZP2 do not affect the initial binding of the sperm to the egg but do significantly inhibit the binding of acrosome-reacted sperm to the ZP, suggesting that ZP2 serves as a secondary receptor for sperm during fertilisation. ${ }^{51}$ In humans, neither E. coli- nor baculovirus-expressed recombinant ZP2 binds to the capacitated acrosome-intact human spermatozoa or induces any significant increase in $\mathrm{AR} .{ }^{52,53}$ The fluorescein isothiocyanate-coupled recombinant human $\mathrm{ZP} 2$ has shown binding to the equatorial region of acrosome-reacted spermatozoa, suggesting that as in mice, human $\mathrm{ZP} 2$ is not involved in the induction of the AR and primarily acts as a secondary sperm receptor. ${ }^{53}$ Employing a highly specific monoclonal antibody (MA-1615) generated against baculovirus-expressed recombinant human ZP2 that is devoid of reactivity in ELISA and western blots with recombinant human $\mathrm{ZP} 3$ and $\mathrm{ZP} 4,{ }^{54}$ purification of human ZP2 from ZPs of unfertilized human oocytes from the assisted reproduction program has been reported. ${ }^{55}$ Purified native human ZP2 binds to the acrosomal region of only acrosome-reacted human spermatozoa, corroborating the findings observed using recombinant ZP2. ${ }^{55}$

\section{ZP3}

The initial adhesion event between the mouse sperm and the ZP is a high affinity event involving about 30000 binding sites (300 molecules $/ \mu \mathrm{m}^{2}$ ) ascribed to $\mathrm{ZP} 3$, which are sufficient to tether a spermatozoon to the extracellular matrix prior to AR induction. ${ }^{56}$ The contact subsequently becomes more tenacious, and the bound spermatozoon undergoes the AR. Among the various physiological and pharmacological inducers of the AR, ZP3 has been accepted as the natural agonist (except in guinea pig) that initiates the AR upon binding of the acrosome-intact mammalian spermatozoa to the $\mathrm{ZP} .{ }^{57}$ Purified mouse ZP3 binds to the anterior head region of the capacitated acrosome-intact spermatozoon, thus acting as a putative primary sperm receptor. ${ }^{47}$ Further, recombinant mouse ZP3 expressed in mammalian cells also decreases sperm-ZP binding and triggers acrosomal exocytosis in capacitated mouse sperm. ${ }^{58}$ In hamsters and humans, ZP3 performs the function of primary sperm receptor. ${ }^{52,53,55,59}$ Studies employing purified native human $\mathrm{ZP} 3,{ }^{60}$ as well as baculovirus-expressed recombinant $Z \mathrm{P} 3,{ }^{32,52,53,61}$ have shown dose-dependent increases in acrosomal exocytosis. Moreover, human ZP3 expressed in mammalian cells also leads to an increase in the AR. ${ }^{62-64}$ However, there are conflicting observations with respect to the efficacy of E. coli-expressed recombinant human ZP3 in inducing the AR. According to one report, E. coli-expressed recombinant ZP3 induces the AR, but a significant increase in the AR is observed only after $18 \mathrm{~h}$ of incubation of the capacitated sperm with the recombinant protein. ${ }^{65}$ Our group has shown that E. coli-expressed recombinant human ZP3, though binding to the anterior head of the capacitated spermatozoon, fails to induce the AR, suggesting that glycosylation of ZP3 is critical for AR induction (Table 1). ${ }^{52,53}$

Delineation of the domain of ZP3 involved in induction of the AR. To understand the role of $\mathrm{ZP} 3$ during fertilisation, it is imperative to delineate the region(s) responsible for its functional activity. Studies with insoluble pronase-digested mouse ZP3 revealed that small glycopeptides (about 1.5-6.0 kDa) are capable of inhibiting the binding of 
sperm to eggs; however, they did not induce the sperm to complete acrosomal exocytosis. ${ }^{66}$ Further, mouse ZP3 was digested with either papain or V8 protease to yield a $55-\mathrm{kDa}$ glycoprotein. ${ }^{67,68}$ The $\sim 55 \mathrm{kDa}$ glycopeptide was derived from the carboxy-terminal half of ZP3 and possessed four or five potential $N$-linked glycosylation sites, and after removal of $N$-linked oligosaccharides by treating with $\mathrm{N}$-glycanase, a $25-\mathrm{kDa}$ glycopeptide was generated. Both untreated and $\mathrm{N}$-glycanase treated glycopeptides inhibited the binding of sperm to eggs and induced sperm to complete the AR in vitro to about the same extent as intact ZP3. These findings suggest that the spermbinding site of mouse ZP3 is located in the carboxy-terminal half of ZP3 and does not involve $N$-linked oligosaccharides. In addition to the biochemical approaches, several molecular genetic approaches have been used to identify the location of the sperm-binding site of ZP3. These approaches were made possible by the successful cloning and sequencing of the mouse $Z p 3$ gene and polypeptide in the late 1980s. ${ }^{69-71}$ Exon swapping and site-directed mutagenesis studies with recombinant mouse ZP3 expressed in an embryonal carcinoma (EC) cell line revealed that the sperm combining site is located in the carboxy-terminal region of ZP3, encoded by exon 7 of the $Z p 3$ gene, ${ }^{72-74}$ which corroborates the biochemical approaches described above.

Recombinant hamster ZP3 expressed in EC cells failed to inhibit in vitro binding of mouse sperm to eggs. However, substitution of the hamster $Z p 3$ exon 7 with mouse $Z p 3$ exon 7 of the recombinant hamster ZP3 led to inhibition of the binding of mouse gametes. ${ }^{75}$ In this context, a fusion construct consisting of human $\operatorname{IgG}(\mathrm{Fc})$ and either exon 7 or 8 of mouse $Z p 3$ were prepared. An EC cell line carrying the recombinant gene was produced that secreted chimeric glycoproteins designated either EC-huIgG $(\mathrm{F} c) /$ mouse ZP3 (7) or EC-huIgG $(\mathrm{Fc}) /$ mouse ZP3 (8). It was observed that only EC-huIgG $(\mathrm{Fc}) /$ mouse ZP3 (7) bound specifically to the plasma membrane overlying the sperm head to a similar extent as mouse ZP3 isolated from eggs, and at nanomolar concentrations EC-huIgG $(\mathrm{Fc})$ /mouse ZP3 (7) inhibited the binding of mouse sperm to eggs in vitro. Collectively, these observations provide evidence that sperm recognize and bind to a region of mouse ZP3 that is encoded by exon 7 and is immediately downstream of its ' $\mathrm{ZP}$ domain'. This conclusion is supported by another recent report on the inhibitory effects of the carboxy-terminal region of recombinant mouse $\mathrm{ZP} 3$ in vitro. ${ }^{76}$ It is of interest that $\mathrm{ZP} 3$ is among the $10 \%$ most different proteins between rodents and humans. ${ }^{77}$ The region of ZP3 encoded by exon 7 has undergone a relatively large number of changes during evolution compared with the remainder of the polypeptide and is a proposed site of positive Darwinian selection. $^{78,79}$

Human ZP3 has a polypeptide backbone of 424 aa, with a signal peptide (SP) at 1-22 aa that facilitates its secretion (Figure $2 \mathrm{a}$ ). A tetra basic consensus furin cleavage site (349-352 aa) is present upstream of a hydrophobic transmembrane-like domain (387-409 aa). In mature human ZP3, both the SP and the transmembrane-like domain are cleaved off. Of 12 cysteine (Cys) residues, eight are conserved in various species. The disulphide linkages of the first four Cys residues form a loop-within-loop motif $\left(\mathrm{Cys}^{46} / \mathrm{Cys}^{140}\right.$ and $\left.\mathrm{Cys}^{78} / \mathrm{Cys}^{99}\right)$, and the second four form a crossover motif $\left(\mathrm{Cys}^{217} / \mathrm{Cys}^{282}\right.$ and $\mathrm{Cys}^{239} /$ $\left.\mathrm{Cys}^{300}\right) .{ }^{80}$ The remaining four Cys residues $\left(\mathrm{Cys}^{319}, \mathrm{Cys}^{321}\right.$, Cys ${ }^{322}$ and $\mathrm{Cys}^{327}$ ) lying within a tight cluster towards the C-terminus are linked by two unassigned disulfide linkages. ${ }^{80}$ Human ZP3 has a conserved domain designated the 'ZP domain' (45-304 aa), which is also present in other zona proteins and several extracellular proteins, such as Tamm-Horsefall protein and $\alpha$ - and $\beta$-tectorin. ${ }^{81,82}$ The human
ZP3 'ZP domain' consists of two conserved subdomains, the N-terminal (45-175 aa) and C-terminal (214-304 aa), separated by a short protease sensitive hinge (Figure $3 \mathrm{a}$ ). To delineate the functional domain of human $\mathrm{ZP} 3$, cDNAs encoding various fragments of human $\mathrm{ZP} 3$ were cloned and expressed using a baculovirus expression system (Figure $3 \mathrm{~b}$ ). Significant induction of the AR was observed when capacitated human sperm were incubated with recombinant human ZP3 fragments corresponding to $214-348$ and $214-305$ aa. ${ }^{83}$ A recombinant ZP3 N-terminal fragment (23-175 aa) failed to induce any significant increase in the AR, suggesting that the functional activity of human ZP3 also resides in its C-terminal domain (Figure 3b).

\section{ZP4}

The mouse $\mathrm{ZP}$ matrix is composed of $\mathrm{ZP} 1, \mathrm{ZP} 2$ and $\mathrm{ZP} 3$, but lacks a $\mathrm{ZP} 4$. Our group, along with others, has investigated the role of $\mathrm{ZP} 4$ in induction of the AR in humans. E. coli-expressed recombinant human ZP4 binds to the anterior head of capacitated acrosome-intact human spermatozoa but does not induce the AR. ${ }^{53}$ On the other hand, baculovirus-expressed recombinant human ZP4 not only binds to the anterior head of capacitated acrosome-intact spermatozoa, but also induces a dose-dependent increase in the $\mathrm{AR}^{32,52,53,61}$ (Table 1). These observations were further confirmed by employing immunoaffinity purified native human ZP4 from solubilized human ZP. ${ }^{55,60}$ However, it may be noted that the purified human $\mathrm{ZP} 4$ fractions from eggs were contaminated with $\mathrm{ZP} 1$, and thus its ability to induce the AR may have been due to the combined effect of both ZP1 and ZP4. The importance of ZP4 either alone or as a hetero-oligomer complex with ZP3 during sperm binding and subsequent induction of the AR has also been demonstrated in Xenopus, ${ }^{84}$ rabbits, ${ }^{85}$ pigs $^{86}$ and non-human primates. ${ }^{87}$ Hence, in humans, ZP4 also acts in conjunction with ZP1 and $\mathrm{ZP} 3$ to induce the $\mathrm{AR}$.

\section{DO DIFFERENT HUMAN ZONA PROTEINS USE THE SAME DOWNSTREAM SIGNALLING PATHWAY?}

As discussed above, in humans (in addition to ZP3), ZP1 and ZP4 also mediate the induction of the AR. ${ }^{31,32,52,53,60,61}$ Using pharmacological inhibitors, subtle differences in the downstream signalling pathways used by the ZP glycoproteins were observed, which are summarized in Table 2. ZP3-mediated induction of the AR in humans is inhibited by pertussis toxin, whereas pertussis toxin does not inhibit ZP1- or ZP4mediated acrosomal exocytosis, which indicates that ZP1/ZP4 act through a $\mathrm{G}_{\mathrm{i}}$ protein-independent pathway. ${ }^{31,52,60}$

T-type VOCC inhibitors (mibefradil and pimozide) inhibit acrosomal exocytosis mediated by ZP3 and a C-terminal fragment of recombinant ZP3, whereas L-type VOCC inhibitors do not. ${ }^{60,83}$ However, ZP1- and ZP4-mediated increases in the AR involve both L- and Ttype VOCCs. ${ }^{31,60}$ (Table 2). Though ZP3 involves activation of adenylate cyclase, PKA is not critical in ZP3 downstream signalling, suggesting redundancy of PKA and supplementation by parallel signalling pathways. Activation of PKA, however, is crucial for ZP1-/ZP4mediated signalling, as its pharmacological inhibitor, $\mathrm{H}-89$, specifically inhibits the ZP1-/ZP4-induced AR. ${ }^{31,60}$ These studies suggest that the downstream signalling pathways involved in the ZP1- and ZP4-induced ARs are very similar but are different from that employed by ZP3 (Table 2). Human ZP1 and ZP4 are paralogues that may have arisen from a common ancestral gene either by gene duplication or exon swapping. ${ }^{11,78,79}$ The aa sequence identity of human ZP1 and $\mathrm{ZP} 4$ is $47 \%$, which further supports the notion that AR induction mediated by ZP1/ZP4 is likely to follow similar downstream signalling events. 
a ZP3 (1-424 aa)

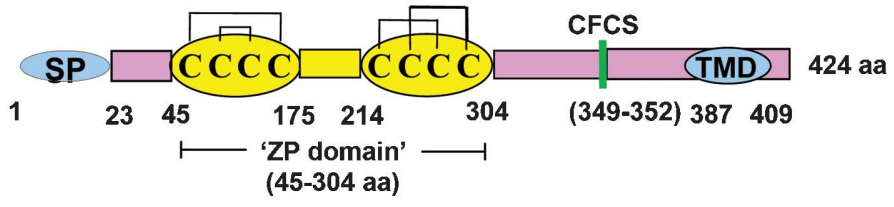

b Human ZP3 fragments

ZP3 N-terminus

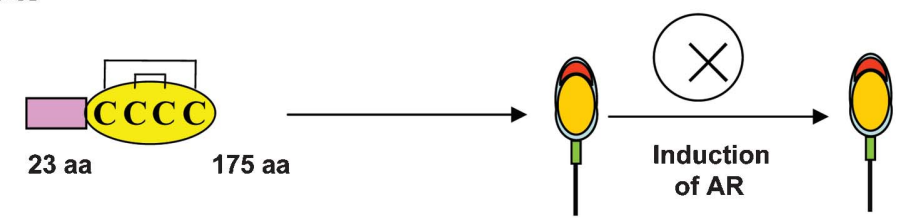

ZP3 C-terminus

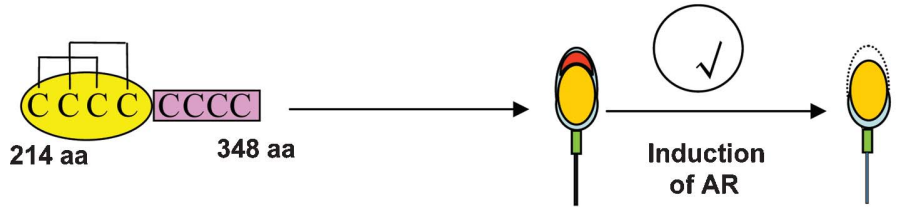

'ZP domain' C-terminus
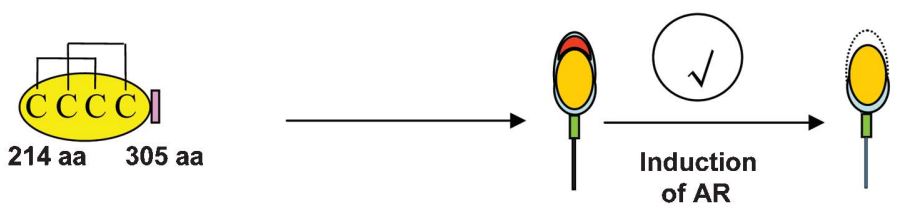

Figure 3 Schematic diagram showing the different domains of human ZP3 and their ability to induce the AR. (a) Human ZP3 has a 424-aa polypeptide backbone comprising an SP (1-22 aa), ZP domain (45-304 aa, yellow), CFCS (349-352 aa, green vertical bar) and TMD (387-409 aa). The ZP domain of ZP3 is composed of N(45-175 aa) and C-terminal (214-304 aa) subdomains. Mapped disulfide linkages between different Cys residues are shown in black lines. (b) An N-terminal ZP3 fragment without the SP (23-175 aa), a C-terminal fragment excluding the CFCS (214-348 aa) and the ZP domain C-terminal subdomain (214-305 aa) were expressed in insect cells and purified recombinant proteins evaluated for AR induction in capacitated human spermatozoa. ${ }^{83}$ The N-terminal fragment of ZP3 failed to induce the AR, whereas both C-terminal fragments induced the AR. AR, acrosome reaction; CFCS, consensus furin cleavage site; C, cysteine; SP, signal peptide; TMD, transmembrane-like domain; ZP, zona pellucida.

\section{ROLE OF OLIGOSACCHARIDE MOIETIES IN SPERM-ZP INTERACTIONS AND INDUCTION OF THE AR}

An understanding of the molecular basis of sperm-egg interactions is still elusive. Various models suggest that it depends on: (i) carbohydrate moieties present on the opposing gamete surfaces; (ii) proteinprotein interactions; and (iii) protein-carbohydrate interactions. The protein-carbohydrate interactions are responsible for $75-80 \%$ of sperm binding to the $\mathrm{ZP}$, and remaining sperm bind by protein-protein interactions. ${ }^{88,89}$

Table 2 Downstream signalling pathways associated with human ZP glycoprotein mediated induction of the acrosome reaction

\begin{tabular}{|c|c|c|c|c|}
\hline \multirow[t]{2}{*}{ Pathway } & \multirow[t]{2}{*}{ Inhibitor } & \multicolumn{3}{|c|}{$\begin{array}{l}\text { Inhibition of induction } \\
\text { of } A R \text { mediated by }\end{array}$} \\
\hline & & ZP3 & $Z P 1$ & $Z P 4$ \\
\hline Extracellular $\mathrm{Ca}^{2+}$ & Ethylene glycol tetraacetic acid & Yes & Yes & Yes \\
\hline $\mathrm{G}_{\mathrm{i}}$ protein-coupled receptor & Pertussis toxin & Yes & No & No \\
\hline T-type VOCCs & Pimozide, amiloride & Yes & Yes & Yes \\
\hline L-type VOCCs & Verapamil, nifedipine & No & Yes & Yes \\
\hline PKA & $\mathrm{H}-89$ & No & Yes & Yes \\
\hline PKC & Chelerythrine & Yes & Yes & Yes \\
\hline
\end{tabular}

Abbreviations: AR, acrosome reaction; PKA, protein kinase A; PKC, protein kinase C; VOCC, voltage-operated calcium channel; ZP, zona pellucida.

\section{Murine models}

Chemically deglycosylated forms of mouse ZP3 fail to induce the AR, suggesting that glycosylation of ZP3 is critical for its functional activity. However, selective removal of $N$-linked oligosaccharides from mouse ZP3 by endo- $\beta$ - $N$-acetyl-D-glucosamine treatment has no effect on the induction of the AR, whereas removal of $O$-linked oligosaccharides by alkaline hydrolysis abrogates its ability to induce the AR. ${ }^{90}$ Initial studies implicated galactose in $\alpha$ - or $\beta$-linkages at the non-reducing terminus of $O$-linked oligosaccharides and $\mathrm{N}$-acetylglucosamine (GlcNAc) in $\beta$-linkages as the sugar determinants on mouse $\mathrm{ZP} 3$ that are responsible for the binding of sperm to the $\mathrm{ZP} .^{91}$ However, mice deficient in glycosyl transferase, which amends terminal galactose in an $\alpha$-linkage, are fully fertile ${ }^{92,93}$ implicating galactose in $\beta$-linkages or GlcNAc or both as critical residues. ${ }^{57}$ Mannose has also been suggested to have an important role in murine sperm receptor activity. ${ }^{94}$ Subsequently, site-directed mutagenesis revealed that glycosylation of serine residues at positions 332 and 334 is critical for the sperm receptor activity of ZP3. ${ }^{73}$

\section{Human}

Binding studies with various lectins suggest that the human ZP matrix has a high concentration of D-mannose. ${ }^{95,96}$ The presence of mannose-binding sites has been reported on human sperm. ${ }^{97,98}$ Several oligosaccharide moieties, such as mannose, GlcNAc, fucose and galac- 
tose, along with complex glycoconjugates bearing selectin-like ligands, are involved in human sperm-egg binding. ${ }^{99,100}$ On the contrary, Chapman and colleagues showed that E. coli-expressed recombinant human ZP3, presumably lacking glycosylation, induced the AR, suggesting that glycosylation of ZP3 may not be an absolute requirement for AR induction. ${ }^{65}$ Our group has expressed recombinant human $\mathrm{ZP} 1, \mathrm{ZP} 2, \mathrm{ZP} 3$ and ZP4 using E. coli and baculovirus expression systems. ${ }^{31,52,53}$ Both E. coli- and baculovirus-expressed recombinant human ZP1, ZP3 and ZP4 conjugated with fluorescein isothiocyanate bind to the anterior head of capacitated acrosome-intact human spermatozoa. ${ }^{31,53}$ The binding patterns of $\mathrm{ZP} 1$ and $\mathrm{ZP} 4$ revealed that a higher percentage of sperm show binding of these proteins to the acrosomal cap as opposed to that seen with ZP3, where equatorial binding predominates in the acrosome-intact spermatozoa. ${ }^{31,53}$ The binding profiles of $E$. coli- and baculovirus-expressed recombinant human ZP1, ZP3 and ZP4 are comparable, suggesting that glycosylation is not critical for binding per se. These results are corroborated by similar findings that the E. coli-expressed bonnet monkey ZP3 and ZP4 bind to monkey sperm. ${ }^{87,101}$

E. coli-expressed recombinant human $\mathrm{ZP} 1, \mathrm{ZP} 3$ and $\mathrm{ZP} 4$ fail to induce any significant increase in the $A R$, whereas baculovirusexpressed recombinant ZP1, ZP3 and ZP4 induce dose-dependent increases in the AR. ${ }^{31,32,52,53,61}$ These studies suggest that glycosylation of human zona proteins is critical for induction of the AR. Expression of recombinant human ZP3 and ZP4 using a baculovirus expression system in the presence of tunicamycin made available these proteins with reduced $N$-linked oligosaccharides. ${ }^{53}$ Incubation of capacitated human sperm with the above recombinant proteins significantly reduces the proteins ability to induce the AR, suggesting that $N$-linked glycosylation of human zona proteins are critical for AR induction. ${ }^{53}$ The importance of $N$-linked glycosylations has been further confirmed using immunoaffinity-purified human ZP3 and ZP4 from solubilized human ZP. Removal of $N$-linked glycosides from human ZP3 and ZP4 by treatment with $\mathrm{N}$-glycosidase F significantly decreases their respective abilities to induce the AR. ${ }^{60}$. Removal of $O$-linked glycans by alkali hydrolysis ( $\beta$-elimination) from either baculovirus-expressed recombinant human $\mathrm{ZP} 3$ and $\mathrm{ZP} 4$ or native human $\mathrm{ZP} 3$ and $\mathrm{ZP} 4$ purified from human eggs has no significant effect on their AR induction ability. ${ }^{53,60}$ Hence, in contrast to mouse, where O-linked glycosylation of ZP3 is critical for AR induction, in humans, $N$-linked glycosylation of ZP1, ZP3 and ZP4 are critical for mediating the AR.

\section{CONCLUSION}

The mouse model for the roles of individual ZP glycoproteins in binding capacitated acrosome-intact spermatozoa and subsequent induction of the AR is not tenable in other species. In mice, $\mathrm{ZP} 3$ is primarily responsible for $A R$ induction. In humans (in addition to $\mathrm{ZP} 3$ ), ZP1 and ZP4 may also be involved in AR induction. In mouse, $O$-linked glycans of $\mathrm{ZP} 3$ are involved in the AR, whereas in humans, $N$-linked glycans of ZP1, ZP3 and ZP4 are critical for AR induction. Hence, it is imperative that each species be investigated in detail to determine the roles of zona proteins during fertilisation.

\section{COMPETING FINANCIAL INTERESTS}

The authors declare no competing financial interests.

\section{ACKNOWLEDGMENTS}

We acknowledge the scientific work of the present and past members of Reproductive Cell Biology Laboratory, National Institute of Immunology, New Delhi, which enabled us to write this review. Financial support from the National Institute of Immunology, New Delhi, Department of Biotechnology,
Government of India, and the Indian Council of Medical Research, Government of India, is gratefully acknowledged.

1 Meizel S. Molecules that initiates or help stimulate the acrosome reaction by their interaction with the mammalian sperm surface. Am J Anat 1985; 174: 285-302.

2 Roldan ER, Murase T, Shi QX. Exocytosis in spermatozoa in response to progesterone and zona pellucida. Science 1994; 266: 1578-81.

3 Gupta SK, Bansal P, Ganguly A, Bhandari B, Chakrabarti K. Human zona pellucida glycoproteins: functional relevance during fertilization. J Reprod Immuno/ 2009; 83: 50-5.

4 Bleil JD, Wassarman PM. Structure and function of the zona pellucida: identification and characterization of the proteins of the mouse oocyte's zona pellucida. Dev Biol 1980; 76: 185-202

5 Hedrick JL, Wardrip NJ. On the macromolecular composition of the zona pellucida from porcine oocytes. Dev Biol 1987; 121: 478-88.

6 Noguchi S, Yonezawa N, Katsumata T, Hashizume K, Kuwayama M et al. Characterization of the zona pellucida glycoproteins from bovine ovarian and fertilized eggs. Biochim Biophys Acta 1994; 1201: 7-14.

7 Goudet G, Mugnier S, Callebaut I, Monget P. Phylogenetic analysis and identification of pseudogenes reveal a progressive loss of zona pellucida genes during evolution of vertebrates. Biol Reprod 2008; 78: 796-806.

8 Hoodbhoy T, Joshi S, Boja ES, Williams SA, Stanley P et al. Human sperm do not bind to rat zonae pellucidae despite the presence of four homologous glycoproteins. J Biol Chem 2005; 280: 12721-31.

9 Izquierdo-Rico MJ, Jimenez-Movilla M, Llop E, Perez-Oliva AB, Ballesta J et al. Hamster zona pellucida is formed by four glycoproteins: ZP1, ZP2, ZP3, and ZP4. J Proteome Res 2009; 8: 926-41.

10 Ganguly A, Sharma RK, Gupta SK. Bonnet monkey (Macaca radiata) ovaries, like human oocytes, express four zona pellucida glycoproteins. Mol Reprod Dev 2008; 75: 156-66.

11 Hughes DC, Barratt CL. Identification of the true human orthologue of the mouse $Z p 1$ gene: evidence for greater complexity in the mammalian zona pellucida? Biochim Biophys Acta 1999; 1447: 303-6.

12 Lefièvre L, Conner SJ, Salpekar A, Olufowobi O, Ashton $\mathrm{P}$ et al. Four zona pellucida glycoproteins are expressed in the human. Hum Reprod 2004; 19: 1580-6.

13 Conner SJ, Lefievre L, Hughes DC, Barratt CL. Cracking the egg: increased complexity in the human zona pellucida. Hum Reprod 2005; 5: 1148-52.

14 Dell A, Morris HR, Easten RL, Patankar M, Clark GF. The glycobiology of gametes and fertilization. Biochem Biophys Acta 1999; 1473: 196-203.

15 Topfer-Petersen E. Carbohydrate-based interactions on the route of a spermatozoon to fertilization. Hum Reprod Update 1999; 5: 314-9.

16 Smith J, Paton IR, Hughes DC, Burt DW. Isolation and mapping the chicken zona pellucida genes: an insight into the evolution of orthologous genes in different species. Mol Reprod Dev 2005; 70: 133-45.

17 Bleil JD, Wassarman PM. Sperm-egg interactions in the mouse: sequence of events and induction of the acrosome reaction by a zona pellucida glycoprotein. Dev Biol 1983; 95: 317-24.

18 Cross NL, Morales P, Overstreet JW, Hanson FW. Induction of acrosome reaction by the human zona pellucida. Biol Reprod 1988; 38: 235-44.

19 Franken DR, Bastiaan HS, Oehninger SC. Physiological induction of the acrosome reaction in human sperm: validation of a microassay using minimal volumes of solubilized, homologous zona pellucida. J Assist Reprod Genet 2000; 17: 374-8.

20 Schuffner AA, Bastiaan HS, Duran HE, Lin ZY, Morshedi M et al. Zona pellucidainduced acrosome reaction in human sperm: dependency on activation of pertussis toxin-sensitive $G_{i}$ protein and extracellular calcium, and priming effect of progesterone and follicular fluid. Mol Hum Reprod 2002; 8: 722-7.

21 Patrat C, Auer J, Fauque P, Leandri RL, Jouannet $\mathrm{P}$ et al. Zona pellucida from fertilised human oocytes induces a voltage-dependent calcium influx and the acrosome reaction in spermatozoa, but cannot be penetrated by sperm. BMC Dev Biol 2006; 6: 59.

22 Doherty CM, Tarchala SM, Radwanska E, de Jonge CJ. Characterization of two second messenger pathways and their interactions in eliciting the human sperm acrosome reaction. J Androl 1995; 16: 36-46.

23 Ward CR, Storey BT, Kopf GS. Activation of a $G_{i}$ protein in mouse sperm membranes by solubilized proteins of the zona pellucida, the egg's extracellular matrix. J Biol Chem 1992; 267: 14061-7.

24 Ward CR, Storey BT, Kopf GS. Selective activation of $G_{i 1}$ and $G_{i 2}$ in mouse sperm by the zona pellucida, the egg's extracellular matrix. J Biol Chem 1994; 269: 13254-8.

25 Walensky LD, Snyder SH. Inositol 1,4,5-trisphosphate receptors selectively localized to the acrosomes of mammalian sperm. J Cell Biol 1995; 130: 857-69.

26 Kopf GS, Wilde MW. Signal transduction processes leading to acrosomal exocytosis in mammalian spermatozoa. Trends Endocrinol Metab 1990; 1: 362-8.

27 Florman HM, Arnoult C, Kazam IG, Li C, O'Toole CM. A perspective on the control of mammalian fertilization by egg-activated ion channels in sperm: a tale of two channels. Biol Reprod 1998; 59: 12-6.

28 Bailey JL, Storey BT. Calcium influx into mouse spermatozoa activated by solubilized mouse zona pellucida, monitored with the calcium fluorescent indicator, fluo-3. Inhibition of the influx by three inhibitors of the zona pellucida induced acrosome reaction: tyrphostin $\mathrm{A} 48$, pertussis toxin, and 3-quinuclidinyl benzilate. Mol Reprod Dev 1994; 39: 297-308. 
29 Arnoult C, Cardullo RA, Lemos JR, Florman HM. Activation of mouse sperm T-type $\mathrm{Ca}^{2+}$ channels by adhesion to the egg zona pellucida. Proc Natl Acad Sci USA 1996; 93: 13004-9.

30 Rockwell PL, Storey BT. Kinetics of onset of mouse sperm acrosome reaction induced by solubilized zona pellucida: fluorimetric determination of loss of $\mathrm{pH}$ gradient between acrosomal lumen and medium monitored by dapoxyl (2-aminoethyl) sulfonamide and of intracellular $\mathrm{Ca}^{2+}$ changes monitored by fluo-3. Mol Reprod Dev 2000; 55: 335-49.

31 Ganguly A, Bukovsky A, Sharma RK, Bansal P, Bhandari B, Gupta SK. In humans, zona pellucida glycoprotein-1 binds to spermatozoa and induces acrosomal exocytosis. Hum Reprod 2010; 25: 1643-56.

32 Jose O, Hernandez-Hernandez O, Chirinos M, Gonzalez-Gonzalez ME, Larrea F et al. Recombinant human ZP3-induced sperm acrosome reaction: evidence for the involvement of T- and L-type voltage-gated calcium channels. Biochem Biophys Res Commun 2010; 395: 530-4.

33 Lievano A, Santi CM, Serrano CJ, Treviño CL, Bellvé AR et al. T-type $\mathrm{Ca}^{2+}$ channels and $\alpha 1 \mathrm{E}$ expression in spermatogenic cells, and their possible relevance to the sperm acrosome reaction. FEBS Lett 1996; 388: 150-4.

34 Santi CM, Darszon A, Hernandez-Cruz A. A dihydropyridine-sensitive T-type $\mathrm{Ca}^{2+}$ current is the main $\mathrm{Ca}^{2+}$ current carrier in mouse primary spermatocytes. Am J Physiol 1996; 271: C1583-93.

35 Arnoult C, Lemos JR, Florman HM. Voltage-dependent modulation of T-type calcium channels by protein tyrosine phosphorylation. EMBO J 1997; 16: 1593-9.

36 Jungnickel MK, Marrero H, Birnbaumer L, Lémos JR, Florman HM. Trp2 regulates entry of $\mathrm{Ca}^{2+}$ into mouse sperm triggered by egg ZP3. Nat Cell Biol 2001; 3:499502.

37 Wes PD, Chevesich J, Jeromin A, Rosenberg C, Stetten G. TRPC1, a human homolog of a Drosophila store-operated channel. Proc Natl Acad Sci USA 1995; 92: 9652-6.

38 De Blas GA, Darszon A, Ocampo AY, Serrano CJ, Castellano LE et al. TRPM8, a versatile channel in human sperm. PLoS One 2009; 4: e6095.

39 Tomes CN, Michaut M, De Blas G, Visconti P, Matti U et al. SNARE complex assembly is required for human sperm acrosome reaction. Dev Biol 2002; 243: 326-38.

40 Michaut M, Tomes CN, De Blas G, Yunes R, Mayorga LS. Calcium-triggered acrosomal exocytosis in human spermatozoa requires the coordinated activation of Rab3 A and $\mathrm{N}$ ethylmaleimide-sensitive factor. Proc Natl Acad Sci USA 2000; 97: 9996-10001.

41 Harrison RA, Roldan ER. Phosphoinositides and their products in the mammalian sperm acrosome reaction. J Reprod Fertil Supp/ 1990; 42: 51-67.

42 Bhandari B, Bansal P, Talwar P, Gupta SK. Delineation of downstream signalling components during acrosome reaction mediated by heat solubilized human zona pellucida. Reprod Biol Endocrinol 2010; 8: 7.

43 Bastiaan H, Franken D, Wranz P. G-protein regulation of the solubilized human zona pellucida-mediated acrosome reaction and zona pellucida binding. J Assist Reprod Genet 1999; 16: 332-6

44 Franken DR, Morales PJ, Habenicht UF. Inhibition of G protein in human sperm and its influence on acrosome reaction and zona pellucida binding. Fertil Steril 1996; 66: 1009-11.

45 Lee MA, Check JH, Kopf GS. A guanine nucleotide-binding regulatory protein in human sperm mediates acrosomal exocytosis induced by the human zona pellucida. Mol Reprod Dev 1992; 31: 78-86.

46 Bielfeld P, Faridi A, Zaneveld LJ, de Jonge CJ. The zona pellucida-induced acrosome reaction of human spermatozoa is mediated by protein kinases. Fertil Steril 1994; 61: 536-41.

47 Bleil JD, Wassarman PM. Mammalian sperm-egg interaction: identification of a glycoprotein in mouse egg zonae pellucidae possessing receptor activity for sperm. Cell 1980; 20: 873-82.

48 Greve JM, Wassarman PM. Mouse egg extracellular coat is a matrix of interconnected filaments possessing a structural repeat. J Mol Biol 1985; 181: 253-64.

49 Sasanami T, Murata T, Ohtsuki M, Matsushima K, Hiyama G et al. Induction of sperm acrosome reaction by perivitelline membrane glycoprotein ZP1 in Japanese quail (Coturnix japonica). Reproduction 2007; 133: 41-9.

50 Okumura $\mathrm{H}$, Kohno Y, Iwata Y, Mori $\mathrm{H}$, Aoki $\mathrm{N}$ et al. A newly identified zona pellucida glycoprotein, ZPD, and dimeric ZP1 of chicken egg envelope are involved in sperm activation on sperm-egg interaction. Biochem J 2004; 384: 191-9.

51 Bleil JD, Greve JM, Wassarman PM. Identification of a secondary sperm receptor in the mouse egg zona pellucida: role in maintenance of binding of acrosome-reacted sperm to eggs. Dev Biol 1988; 128: 376-85.

52 Chakravarty S, Suraj K, Gupta SK. Baculovirus-expressed recombinant human zona pellucida glycoprotein-B induces acrosomal exocytosis in capacitated spermatozoa in addition to zona pellucida glycoprotein-C. Mol Hum Reprod 2005; 11: 365-72.

53 Chakravarty S, Kadunganattil S, Bansal P, Sharma RK, Gupta SK. Relevance of glycosylation of human zona pellucida glycoproteins for their binding to capacitated human spermatozoa and subsequent induction of acrosomal exocytosis. Mol Reprod Dev 2008; 75: 75-88.

54 Bukovsky A, Gupta SK, Bansal P, Chakravarty S, Chaudhary M et al. Production of monoclonal antibodies against recombinant human zona pellucida glycoproteins: utility in immunolocalization of respective zona proteins in ovarian follicles. $J$ Reprod Immunol 2008; 78: 102-14.

55 Chiu PC, Wong BS, Lee CL, Pang RT, Lee KF et al. Native human zona pellucida glycoproteins: purification and binding properties. Hum Reprod 2008; 23: 1385-93.

56 Thaler CD, Cardullo RA. The initial molecular interaction between mouse sperm and the zona pellucida is a complex binding event. J Biol Chem 1996; 271: 23289-97.

57 Wassarman PM. Mammalian fertilization: molecular aspects of gamete adhesion, exocytosis, and fusion. Cell 1999; 96: 175-83.
58 Beebe SJ, Leyton L, Burks D, Ishikawa M, Fuerst T et al. Recombinant mouse ZP3 inhibits sperm binding and induces the acrosome reaction. Dev Biol 1992; 151: 48-54.

59 Moller CC, Bleil JD, Kinloch RA, Wassarman PM. Structural and functional relationships between mouse and hamster zona pellucida glycoproteins. Dev Biol 1990; 137: 276-86.

60 Chiu PC, Wong BS, Chung MK, Lam KK, Pang RT et al. Effects of native human zona pellucida glycoproteins 3 and 4 on acrosome reaction and zona pellucida binding of human spermatozoa. Biol Reprod 2008; 79: 869-77.

61 Caballero-Campo P, Chirinos M, Fan XJ, González-González ME, Galicia-Chavarría M et al. Biological effects of recombinant human zona pellucida proteins on sperm function. Biol Reprod 2006; 74: 760-8.

62 van Duin M, Polman JE, de Breet IT, van Ginneken K, Bunschoten $\mathrm{H}$ et al. Recombinant human zona pellucida protein ZP3 produced by chinese hamster ovary cells induces the human sperm acrosome reaction and promotes sperm-egg fusion. Biol Reprod 1994; 51: 607-17.

63 Dong KW, Chi TF, Juan YW, Chen CW, Lin Z et al. Characterization of the biologic activities of a recombinant human zona pellucida protein 3 expressed in human ovarian teratocarcinoma (PA-1) cells. Am J Obstet Gynecol 2001; 184: 835-43.

64 Bray C, Son JH, Kumar P, Harris JD, Meizel S. A role for the human sperm glycine receptor $/ \mathrm{Cl}^{-}$channel in acrosome reaction initiated by recombinant ZP3. Biol Reprod 2002; 66: 91-7.

65 Chapman N, Kessopoulou E, Andrews P, Hornby D, Barratt CR. The polypeptide backbone of recombinant human zona pellucida glycoprotein-3 initiates acrosomal exocytosis in human spermatozoa in vitro. Biochem J 1998; 330: 839-45.

66 Florman HM, Bechtol KB, Wassarman PM. Enzymatic dissection of the functions of the mouse egg's receptor for sperm. Dev Biol 1984; 106: 243-55.

67 Rosiere TK, Wassarman PM. Identification of a region of mouse zona pellucida glycoprotein mZP3 that possesses sperm receptor activity. Dev Biol 1992; 154: 309-17.

68 Litscher ES, Wassarman PM. Characterization of mouse ZP3-derived glycopeptide, gp55, that exhibits sperm receptor and acrosome reaction-inducing activity in vitro. Biochemistry 1996; 35: 3980-5.

69 Kinloch RA, Roller RJ, Fimiani CM, Wassarman DA, Wassarman PM. Primary structure of the mouse sperm receptor polypeptide determined by genomic cloning. Proc Nat Acad Sci USA 1988; 85: 6409-13.

70 Ringuette MJ, Chamberlin ME, Baur AW, Sobieski DA, Dean J. Molecular analysis of cDNA coding for ZP3, a sperm binding protein of the mouse zona pellucida. Dev Biol 1988; 127: 287-95.

71 Kinloch RA, Wassarman PM. Nucleotide sequence of the gene encoding zona pellucida glycoprotein ZP3 - the mouse sperm receptor. Nucleic Acids Res 1989; 17: 2861-3.

72 Kinloch RA, Sakai Y, Wassarman PM. Mapping the mouse ZP3 combining site for sperm by exon swapping and site-directed mutagenesis. Proc Natl Acad Sci USA 1995; 92: 263-7.

73 Chen J, Litscher ES, Wassarman PM. Inactivation of the mouse sperm receptor, mZP3, by site-directed mutagenesis of individual serine residues located at the combining site for sperm. Proc Natl Acad Sci USA 1998; 95: 6193-7.

74 Kinloch RA, Mortillo S, Stewart CL, Wassarman PM. Embryonal carcinoma cells transfected with ZP3 genes differentially glycosylate similar polypeptides and secrete active mouse sperm receptor. J Cell Biol 1991; 115: 655-64.

75 Williams Z, Litscher ES, Jovine L, Wassarman PM. Polypeptide encoded by mouse ZP3 exon-7 is necessary and sufficient for binding of mouse sperm in vitro. J Cell Physiol 2006; 207: 30-9.

76 Li D, Cao S, Xu C. Polypeptide backbone derived from carboxyl terminal of mouse ZP3 inhibits sperm-zona binding. Mol Reprod Dev 2007; 74: 1327-36.

77 Aagaard JE, Yi X, MacCoss MJ, Swanson WJ. Rapidly evolving zona pellucida domain proteins are a major component of the vitelline envelope of abalone eggs. Proc Natl Acad Sci USA 2006; 103: 17302-7.

78 Swanson WJ, Yang Z, Wolfner MF, Aquadro CF. Positive Darwinian selection drives the evolution of several female reproductive proteins in mammals. Proc Natl Acad Sci USA 2001; 98: 2509-14.

79 Swanson WJ, Nielsen R, Yang Q. Pervasive adaptive evolution in mammalian fertilization proteins. Mol Biol Evol 2003; 20: 18-20.

80 Zhao M, Boja ES, Hoodbhoy T, Nawrocki J, Kaufman JB et al. Mass spectrometry analysis of recombinant human ZP3 expressed in glycosylation deficient $\mathrm{CHO}$ cells. Biochemistry 2004; 43: 12090-104.

81 Jovine L, Qi H, Williams Z, Litscher ES, Wassarman PM. The ZP domain is a conserved module for polymerization of extracellular proteins. Nat Cell Biol 2002; 4: 457-61.

82 Jovine L, Darie CC, Litscher ES, Wassarman PM. Zona pellucida domain proteins. Annu Rev Biochem 2005; 74: 83-114.

83 Bansal P, Chakrabarti K, Gupta SK. Functional activity of human ZP3 primary sperm receptor resides toward its C-terminus. Biol Reprod 2009; 81: 7-15.

84 Vo LH, Hedrick JL. Independent and hetero-oligomeric-dependent sperm binding to egg envelope glycoprotein ZPC in Xenopus laevis. Biol Reprod 2000; 62: 766-74.

85 Prasad SV, Wilkins B, Skinner SM, Dunbar BS. Evaluating zona pellucida structure and function using antibodies to rabbit $55 \mathrm{kDa}$ ZP protein expressed in baculovirus expression system. Mol Reprod Dev 1996; 43: 519-29.

86 Yurewicz EC, Sacco AG, Gupta SK, Xu N, Gage DA. Hetero oligomerization-dependent binding of pig oocyte zona pellucida glycoproteins ZPB and ZPC to boar sperm membrane vesicles. J Biol Chem 1998; 273: 7488-94.

87 Govind CK, Gahlay GK, Choudhury S, Gupta SK. Purified and refolded recombinant bonnet monkey (Macaca radiata) zona pellucida glycoprotein-B expressed in Escherichia coli binds to spermatozoa. Biol Reprod 2001; 64: 1147-52. 
88 Macek MB, Shur BD. Protein-carbohydrate complementarity in mammalian gamete recognition. Gamete Res 1988; 20: 93-109.

89 Clark GF, Dell A. Molecular models for murine sperm-egg binding. J Biol Chem 2006 281: 13853-6.

90 Florman HM, Wassarman PM. O-linked oligosaccharides of mouse egg ZP3 account for its sperm receptor activity. Cell 1985; 41: 313-24.

91 Bleil JD, Wassarman PM. Galactose at the nonreducing terminus of $O$-linked oligosaccharides of mouse egg zona pellucida glycoprotein ZP3 is essential for the glycoprotein's sperm receptor activity. Proc Natl Acad Sci USA 1988; 85: 6778-82.

92 Liu C, Litscher ES, Wassarman PM. Zona pellucida glycoprotein mZP3 bioactivity is not dependent on the extent of glycosylation of its polypeptide or on sulfation and sialylation of its oligosaccharides. J Cell Sci 1997; 110: 745-52.

93 Thall AD, Maly P, Lowe JB. Oocyte Gal $\alpha 1,3 \mathrm{Gal}$ epitopes implicated in sperm adhesion to the zona pellucida glycoprotein ZP3 are not required for fertilization in the mouse. $J$ Biol Chem 1995; 270: 21437-40.

94 Cornwall GA, Tulsiani DR, Orgebin-Crist MC. Inhibition of the mouse sperm surface alpha-D-mannosidase inhibits sperm-egg binding in vitro. Biol Reprod 1991; 44 913-21.
95 Maymon BB, Maymon R, Ben Nun I, Ghetler Y, Shalgi R et al. Distribution of carbohydrates in the zona pellucida of human oocytes. J Reprod Fertil 1994; 102: 81-6.

96 Jimenez-Movilla M, Aviles M, Gomez-Torres MJ, Fernández-Colom PJ, Castells MT. Carbohydrate analysis of the zona pellucida and cortical granules of human oocytes by means of ultrastructural cytochemistry. Hum Reprod 2004; 19: 1842-55.

97 Youssef HM, Doncel GF, Bassiouni BA, Acosta AA. Mannose-binding sites on human spermatozoa and sperm morphology. Fertil Steril 1996; 66: 640-5.

98 Furlong LI, Veaute C, Vazquez-Levin MH. Binding of recombinant human proacrosin/ acrosin to zona pellucida glycoproteins. II. Participation of mannose residues in the interaction. Fertil Steril 2005; 83: 1791-6.

99 Miranda PV, Gonzalez-Echeverria F, Marin-Briggiler CI, Brandelli A, Blaquier JA et al. Glycosidic residues involved in human sperm-zona pellucida binding in vitro. $\mathrm{Mol}$ Hum Reprod 1997; 3: 399-404.

100 Oehninger S, Patankar M, Seppala M, Clark GF. Involvement of selectin-like carbohydrate binding specificity in human gamete interaction. Andrologia 1998; 30: 269-74.

101 Gahlay GK, Srivastava N, Govind CK, Gupta SK. Primate recombinant zona pellucida proteins expressed in Escherichia coli bind to spermatozoa. J Reprod Immunol 2002, 53: 67-77. 